\title{
3 Research Square

\section{Prevalence of Overweight, Obesity and Metabolic Abnormalities Among 12-15 Year Age Group in an Urban City in Sri-Lanka}

\author{
Vasana Kiridana ( $\sim$ vkiridana@yahoo.co.uk) \\ University of Peradeniya https://orcid.org/0000-0002-3388-1954
}

Ruchira Karunaratne

Department of Paediatrics, faculty of Medicine, University of Peradeniya Jagath Chaminda Ranasinghe

Ministry of Health

Thilini Surenika Munasinghe

University of Peradeniya Faculty of Medicine

\section{Umeshi Ishanthika Karunadasa}

Department of paediatrics, Faculty of Medicine, University of Peradeniya

\section{Gihani Udeshika Vidanapathirana}

University of Peradeniya Faculty of Medicine

\section{Sameera Prabhath Abeygoonaratne}

Ministry of Health

\section{Madhawa Perera}

Department of Physiology, faculty of Medicine, University of Peradeniya

Anuradha Bogahapitiya

Ministry of Health

Geethanjalee Jayathilaka

Ministry of Health: Gobierno de Chile Ministerio de Salud

Jeewani Udupihilla

Department of radiology, faculty of medicine, University of Peradeniya

\section{Sampath Tennakoon}

Department of community medicine, faculty of Medicine, university of Peradeniya

Chandra Abeysekera

Department of paediatrics, Faculty of medicine, University of Peradeniya

Research article

Keywords: Overweight, Obesity, Metabolic syndrome, Fatty liver, Paediatric 
Posted Date: October 12th, 2020

DOl: https://doi.org/10.21203/rs.3.rs-89303/v1

License: (c) (i) This work is licensed under a Creative Commons Attribution 4.0 International License. Read Full License

Version of Record: A version of this preprint was published at Sri Lanka Journal of Medicine on July 1st, 2021. See the published version at https://doi.org/10.4038/sljm.v30i1.232. 


\section{Abstract}

Objectives

To determine the prevalence of childhood overweight, obesity and metabolic abnormalities among children aged 12-15 years within the schools in Kandy Municipality area, Sri Lanka.

Design

Cross- sectional observational study.

Setting

Randomly selected schools in Kandy municipality area

Methods

The anthropometric measurements of 1766 school children were taken and those who were overweight or obese were recruited for further evaluation of metabolic abnormalities.

Results

There were 1053 (59.62\%) boys and $713(40.37 \%)$ girls of whom $258(14.60 \%)$ were overweight or obese (7.81\% overweight and $6.79 \%$ obese). This included 106 girls of whom, 64 were overweight and 42 were obese and 152 boys of whom, 74 and 78 were overweight and obese respectively. Central obesity was seen in $16.93 \%$ and $5.01 \%$ of them had normal body mass index. Eighty-five children out of the 258 with body mass index $>85^{\text {th }}$ percentile reported for further evaluation and the prevalence of metabolic syndrome among them was $11.67 \%$ ( 5 girls and 5 boys). When borderline and abnormal levels of lipids were taken together, more than $50 \%$ of overweight and obese children were found to have dyslipidaemia. Elevated Alanine Amino Transaminase and Aspartate Amino Transaminase levels were reported in 33 (38.82\%) and 7 (8.24\%) respectively. Evidence of fatty liver was present in $34.69 \%$ based on abdominal ultra sound scan findings.

Conclusion

While prevalence rates of overweight, obesity and metabolic syndrome are comparable with other urban settings in the country as well as neighbouring countries in Asia, the study highlights the detection of lipid abnormalities suggestive of familial hyperlipidaemia which warrants further evaluation. NAFLD is also identified as a significant comorbidity. Central obesity is underestimated by British standards.

\section{Introduction}

Childhood obesity has been increasing world-wide over the past few decades [1]. A study on North-Indian urban children reported prevalence of overweight and obesity at $9.7 \%$ and $3.3 \%$ respectively [2]. According 
to a similar study conducted in Pakistan, $12 \%$ of school children were obese and $8 \%$ were overweight [3]. A study on primary school children of urban Nepal showed that $18.6 \%$ of children were overweight and $7.1 \%$ obese [4]. Prevalence of obesity and overweight among school-aged children in Bangladesh was respectively $3.5 \%$ and $9.5 \%$ [5].

A survey conducted in the Colombo district of Sri-Lanka during 2004 to 2005 showed that the prevalence of obesity among boys and girls aged $5-15$ years were $5.7 \%$ and $6.4 \%$ respectively [6]. A cross sectional descriptive study from Negombo, revealed that $27 \%$ of girls and $19 \%$ of boys aged $10-15$ years were obese [7]. Prevalence of overweight and obesity were respectively $9.4 \%$ and $5.5 \%$ among teenage-girls in Batticaloa which in addition showed a $21.6 \%$ prevalence of central obesity [8]. Collectively, literature acknowledged that the prevalence of childhood obesity has been increasing over the time and shows a regional variation $[6,9]$.

The growing prevalence of obesity among Sri-Lankan children, particularly central obesity has led to the emergence of a constellation of metabolic derangements including dyslipidaemia, insulin resistance and non-alcoholic fatty liver disease (NAFLD) $[8,10,11]$. The link between central obesity, metabolic syndrome and type 2 diabetes is increasingly recognized in children [12]. The predominant dyslipidaemia pattern in childhood obesity, a combination of hypertriglyceridaemia and low high density lipoprotein cholesterol, together with central obesity, hyperglycaemia and hypertension represent a clustering of atherogenic risk factors described as metabolic syndrome [13]. The prevalence of metabolic syndrome in Colombo, Sri Lanka was $1.6 \%$ and $22.1 \%$ of them were obese [14]. NAFLD is a potential cause of chronic liver disease [15] and its prevalence was recently studied in Ragama Medical Officer of Health area reporting $8.4 \%$ of adolescents suffer with NAFLD [10].

Although some literature is available regarding the prevalence of childhood obesity in Sri-Lanka, there are no published studies in Kandy which is one of the highly populated urban cities in the country. Moreover, a very few authors have reported the prevalence of metabolic syndrome and NAFLD in childhood. Thus, our objective was not only to estimate the prevalence of overweight, obesity and central obesity among children aged 12-15 years attending the schools in Kandy Municipality area, but also to explore the prevalence of metabolic abnormalities and non-alcoholic fatty liver disease among overweight and obese.

\section{Methods}

\section{Sampling}

Multistage-cluster sampling method was used to recruit a total of 1766 school children aged 12-15 years. Minimum sample size required for the study was calculated [16] considering the prevalence of obesity as $5 \%$ (precision 0.05 , confidence-level 95\%) and doubling the amount to minimize the clustering effect. The size of the sample was further inflated by $10 \%$ for contingencies. 
A $20 \%$ sample from type $1 A B, 1 C$ and type 2 schools in the Kandy municipality area was selected using the stratified random sampling method proportionate to the population. All students from grade 8,9 and 10 classes from the selected schools were listed separately for each grade where each class was a cluster. The cluster size was decided as 20 therefore a minimum of 50 clusters were required.

\section{Study design:}

This cross-sectional observational study was conducted in selected schools from November 2018 to June 2019. Body weight was measured to the nearest $0.1 \mathrm{~kg}$ using a pre-calibrated OMRON (HBF 510W) body composition monitor and height was quantified to the $0.1 \mathrm{~cm}$ using the GIMA portable stadiometer. Waist circumference was measured with a flexible measuring tape with the subject standing upright, feet slightly apart and abdomen relaxed. Waist circumference was taken at the narrowest point of the torso above the umbilicus and below the rib cage. Body fat percentage was measured by OMRON (HBF 510W) body composition monitor using the Bioelectrical Impedance Analysis technique.

Participants whose Body Mass Index (BMI) was above $85^{\text {th }}$ percentile for age and sex were recruited to evaluate for metabolic abnormalities $[17,18]$. Their blood samples were analysed using fully automated Biochemical analyser (HumaStar 150 SR-Human) for fasting lipid profile, fasting blood sugar, and liver enzymes (Alanine Amino Transaminase and Aspartate Amino Transaminase). Real-time ultrasonography of abdomen was done utilizing Toshiba TUS-A 300 Ultrasound Machine with $3.5 \mathrm{MHz}$ convex transducer.

Metabolic syndrome was diagnosed according to International Diabetes Federation criteria [19]. Overweight and obesity were diagnosed based on BMI cut-offs of World Health Organization (WHO) [18]. Waist Circumference cut-offs by British growth standards were used [20]. Percentages total body fat of $35 \%$ for girls and $25 \%$ for boys were considered as cut-off values for obesity related morbidity $[21,22]$.

\section{Data analysis:}

Data was analysed using Microsoft Excel and SPSS version 20. Descriptive statistics and means with standard deviation were reported. Chi square test was used to determine the association of the presence of fatty liver with elevated liver enzymes.

\section{Results}

Anthropometric measurements were taken in 1766 children who comprised of 1053 (59.62\%) boys, 713 $(40.37 \%)$ girls. Average BMI of the sample was $19.0 \pm 7.0 \mathrm{~kg} / \mathrm{m}^{2}$ and mean waist circumference was 65.0 $\pm 9.3 \mathrm{~cm}$. In the total sample, $258(14.60 \%)$ were overweight or obese.

Prevalence of obesity was 120 (6.8\%) and prevalence of overweight was 138 (7.81\%). This included 106 girls of whom, 64 (8.98\%) were overweight and 42 (5.89\%) were obese and 152 boys of whom, 74 (7.03\%) and $78(7.41 \%)$ were overweight and obese respectively. Higher prevalence of overweight and obesity was seen in $>14-15$ age group compared to others (Table 01 ). 
Table 01: Overweight and obesity among school children.

\begin{tabular}{|c|c|c|c|c|c|c|c|}
\hline & Total & $\begin{array}{l}\text { Overweight and } \\
\text { obese }\end{array}$ & $\begin{array}{l}\text { Percentage } \\
(\%)\end{array}$ & Overweight & $\begin{array}{l}\text { Percentage } \\
(\%)\end{array}$ & Obese & $\begin{array}{l}\text { Percentage } \\
(\%)\end{array}$ \\
\hline \multicolumn{8}{|l|}{ Girls } \\
\hline $\begin{array}{l}12- \\
13\end{array}$ & 253 & 39 & 15.42 & 23 & 9.09 & 16 & 6.32 \\
\hline $\begin{array}{l}>13- \\
14\end{array}$ & 267 & 36 & 13.48 & 21 & 7.87 & 15 & 5.62 \\
\hline $\begin{array}{l}>14- \\
15\end{array}$ & 193 & 31 & 16.06 & 20 & 10.36 & 11 & 5.70 \\
\hline Total & 713 & 106 & 14.87 & 64 & 8.98 & 42 & 5.89 \\
\hline \multicolumn{8}{|l|}{ Boys } \\
\hline $\begin{array}{l}12- \\
13\end{array}$ & 345 & 48 & 13.91 & 22 & 6.38 & 26 & 7.54 \\
\hline $\begin{array}{l}>13- \\
14\end{array}$ & 407 & 57 & 14 & 25 & 6.14 & 32 & 7.86 \\
\hline $\begin{array}{l}>14- \\
15\end{array}$ & 301 & 47 & 15.61 & 27 & 8.97 & 20 & 6.64 \\
\hline Total & 1053 & 152 & 14.43 & 74 & 7.03 & 78 & 7.41 \\
\hline \multicolumn{8}{|c|}{ Girls and boys } \\
\hline $\begin{array}{l}12- \\
13\end{array}$ & 598 & 87 & 14.55 & 45 & 7.53 & 42 & 7.02 \\
\hline $\begin{array}{l}>13- \\
14\end{array}$ & 674 & 93 & 13.80 & 46 & 6.82 & 47 & 6.97 \\
\hline $\begin{array}{l}>14- \\
15\end{array}$ & 494 & 78 & 15.79 & 47 & 9.51 & 31 & 6.28 \\
\hline Total & 1766 & 258 & 14.61 & 138 & 7.81 & 120 & 6.80 \\
\hline
\end{tabular}

Total body fat percentages in overweight or obese children (152 boys, 106 girls), which revealed 78 (51.32\%) boys and 92 (86.79\%) girls were beyond the cut-off values for their gender.

According to British standards, waist circumference above $90^{\text {th }}$ percentile was seen in 299 (16.93\%). Among overweight and obese children, $223(86.43 \%)$ had waist circumference above $90^{\text {th }}$ percentile. Among children who had normal BMI, $76(5.04 \%)$ had waist circumference above $90^{\text {th }}$ percentile.

Out of the 258 children who were overweight or obese, only 85 children reported for blood investigations. Prevalence of metabolic syndrome of $11.76 \%$ ( 5 girls and 5 boys) was found in this group of children. 
Waist circumference above $90^{\text {th }}$ percentile, fasting blood sugar $\geq 100 \mathrm{mg} / \mathrm{dl}$, high density lipoprotein $\leq$ $40 \mathrm{mg} / \mathrm{dl}$ and triglycerides $\geq 150 \mathrm{mg} / \mathrm{dl}$ were seen in 71 (83.52\%), 8 (9.41\%), 25 (29.41\%) and 21 (24.71\%) respectively. All participants were normotensive.

Acceptable, borderline and abnormal levels in the fasting lipid profiles were defined as per cut-offs provided by American College of Cardiology [23] and proportions of children in each category are shown in Table 02. A considerable number of children in our sample had high levels of cholesterol, triglycerides, low density lipoprotein and low levels of high density lipoprotein.

Table 02: Lipid patterns of children $(n=85)$.

\begin{tabular}{|llll|}
\hline & Acceptable & Borderline & Abnormal \\
\hline Total cholesterol & $41(48.24 \%)$ & $19(22.35 \%)$ & $25(29.41 \%)$ \\
\hline Triglycerides & $22(25.88 \%)$ & $35(41.18 \%)$ & $28(32.94 \%)$ \\
\hline Low density lipoprotein cholesterol & $42(49.41 \%)$ & $20(23.53 \%)$ & $23(27.06 \%)$ \\
\hline High density lipoprotein cholesterol & $28(32.94 \%)$ & $32(37.65 \%)$ & $25(29.41 \%)$ \\
\hline
\end{tabular}

Elevated Alanine Amino Transaminase and Aspartate Amino Transaminase levels were reported in 33 (38.82\%) and 7 (8.24\%) respectively from the 85 children who underwent blood investigations [24].

Only 49 children reported for ultrasound scan of abdomen. Grade 1 fatty liver was seen in 14 (28.57\%) while grade 2 fatty liver was seen in $3(6.12 \%)$. From these children, 19 (38.78\%) had elevated Alanine Amino Transaminase levels. All who had grade 2 fatty liver reported to have elevated Alanine Amino Transaminase. There was a correlation between elevated Alanine Amino Transaminase and the presence of fatty liver $(p=0.04)$.

\section{Discussion}

The study found that nearly one in seven school children (14.6\%) aged 12-15 years in this urban Sri Lankan setting are either overweight or obese. The prevalence of overweight and obesity which were $7.81 \%$ and $6.8 \%$ respectively are in congruence with findings from other parts of the country [8]. However, neighbouring countries like Pakistan and Nepal report a higher prevalence of overweight $[3,4]$. This contrast in the findings could be attributed to the slight variation in the age range of the study populations.

The study revealed a prevalence of metabolic syndrome among overweight and obese children at $11.76 \%$ which is congruent with the findings from other urban settings of the country [14]. The prevalence of metabolic syndrome among Sri-Lankan adolescents is significantly lower compared to obese adolescents in India [25]. 
Waist circumference above 90th percentile was found at a prevalence of $86.43 \%$ of the overweight and obese population surfacing the increased metabolic risk in this age group. The waist circumference was interpreted according to the British standards since country specific nomograms are unavailable. Waist circumference could vary among diverse ethnic groups $[26,27]$. International Diabetes Federation, recommends using ethnic specific waist circumference charts where available. The validity and reliability of the British standards for waist circumference have not been adequately examined for Sri Lankan children which could be a limitation of our study. Waist circumference cut-offs outlined in a cohort of urban Sri Lankan children, identified $43.88 \%$ of central obesity in our total study population while British waist circumference cut-offs detected only $16.93 \%$ [21]. Hence there is a potential for both cut-offs to either over estimate or under estimate central obesity in Sri Lankan children. Therefore, further studies from different areas of the country would be useful to determine waist circumference standards for SriLankan children.

Hypertriglyceridaemia and low high density lipoprotein cholesterol levels in the abnormal range were found in one in three overweight children. However, fasting blood sugar was abnormal only in $9.41 \%$ and none were hypertensive. These findings, while demonstrating a contrasting difference in the prevalence of different metabolic risk factors, highlights the abundance of central obesity with dyslipidaemia in this urban child population.

The lipid pattern in this overweight \& obese cohort, when borderline and abnormal cut-offs taken together revealed adiposity related dyslipidaemia pattern (high triglycerides with low high density lipoprotein cholesterol) in more than two third. The prevalence of high cholesterol levels and high low density lipoprotein cholesterol levels were found in nearly $50 \%$ of this population thus surfacing the possibility of the existence of familial hyperlipidaemia in addition to adiposity related dyslipidaemia. Further studies are needed to identify the lipid pattern in Sri Lankan child population. Even though NAFLD was detected in $34.69 \%$ it is difficult to derive a significance due to under reporting for ultra sound scan procedure which could be attributed to lack of awareness among general public regarding obesity and its implications.

\section{Conclusion}

Overweight and obesity prevails at $14.6 \%$ with metabolic syndrome at $11.67 \%$ among the children aged 12-15 years in this urban area which are comparable with the prevalence rates reported from similar urban settings in the island. Presence of central obesity in 5.04\% among children with normal BMI implies that the prevailing BMI cut-offs may under estimate adiposity in Asian ethnicities. Presence of elevated low density lipoprotein cholesterol in $27.06 \%$ is an eye-opener as to the existence of familial hyperlipidaemia in addition to adiposity related dyslipidaemia. 
Findings of this study contribute to the national data base of the non-communicable disease prevention programme and assimilation of data from different parts of the country would prompt the concerned stakeholders to develop a strategic preventive programme. Further studies are recommended to determine the prevalence of central obesity, NAFLD and the dyslipidaemia pattern among Sri-Lankan children.

\section{Abbreviations}

BMI: Body Mass Index, IOTF: International Obesity Task Force, NAFLD: Non Alcoholic Fatty Liver Disease, IDF: International Diabetes Federation, OW: Overweight, WC: Waist Circumference, TG: Triglycerides, MS: Metabolic Syndrome, FBS: Fasting blood sugar, ALT: Alanine Amino Transaminase, AST: Aspartate Amino Transaminase, HDL-C high density lipoprotein cholesterol, LDL-C: low density lipoprotein cholesterol

\section{Declarations}

Acknowledgements: We would like to acknowledge the academic and non-academic staff members at the Department of Paediatrics and the staff of Clinical research Laboratory Faculty of Medicine, University of Peradeniya, Sri Lanka for their support during the research project. We also thank the principals and class-teachers of selected schools in Kandy Municipality area along with the selected children and their parents.

Authors' contributions: VK and CA conceptualized the study, VK, JR, RK, TM, UK, SA and MP collected the data, VK, RK and TM analysed and interpreted the data, VK, RK, GV and GJ drafted the manuscript, VK, ST and JU refined methodologies and tools, VK, MP, GV and RK revised the manuscript, VK, CA and JR finalized the manuscript. All authors read and approved the final manuscript.

Funding: The study was not funded by any source or funding agency.

There is no competing interest from the authors for the publication.

Availability of data and materials: All data is available in the paper. The datasets generated during and/or analysed during the current study are available from the corresponding author on reasonable request.

Ethics approval and consent to participate: Ethics approval for this study was obtained from the ethical review board of the Faculty of Medicine, University of Peradeniya. Written permission was taken from the Zonal Education Office, Kandy. Written informed consent to participate was obtained from all the respondent parents and school authority before data collection.

\section{References}


1. Di Cesare M, Sorić M, Bovet P, Miranda JJ, Bhutta Z, Stevens GA, et al. The epidemiological burden of obesity in childhood: A worldwide epidemic requiring urgent action. BMC Med. 2019;17:1-20.

2. Kaur S, Sachdev HPS, Dwivedi SN, Lakshmy R, Kapil U. Prevalence of overweight and obesity amongst school children in Delhi, India. Asia Pac J Clin Nutr. 2008;17:592-6.

3. Ahmed J, Laghari A, Naseer M, Mehraj V. Prevalence of and factors associated with obesity among Pakistani schoolchildren: a school-based, cross-sectional study. East Mediterr Heal J. 2013;19:2427.

4. Karki A, Shrestha A, Subedi N. Prevalence and associated factors of childhood overweight/obesity among primary school children in urban Nepal. BMC Public Health. 2019;19:1-12.

5. Bulbul T, Hoque M. Prevalence of childhood obesity and overweight in Bangladesh: Findings from a countrywide epidemiological study. BMC Pediatr. 2014;14:1-8.

6. Wickramasinghe VP, Lamabadusuriya SP, Cleghorn GJ, Davies PS. Validity of currently used cutoff values of body mass index as a measure of obesity in Sri Lankan children. Ceylon Med J. 2009;54:114-9.

7. Warnakulasuriya LS, Fernando MAM, Adikaram AVN, Thawfeek ARM, Anurasiri WML, Elisabet R, et al. Assessment of Nutritional Status in Sri Lankan Children: Validity of Current Anthropometry Cutoffs? Asia-Pacific J Public Heal. 2019;31:633-42.

8. Karuppiah D, Markandu M. Prevalence of obesity, overweight and central obesity among adolescent girls in national school in Batticaloa district, Sri Lanka. Sri Lanka J Diabetes Endocrinol Metab. 2018;8:17.

9. Wickramasinghe VP, Arambepola C, Bandara DMPS, Abeysekera M, Kuruppu S, Dilshan P, et al. Validity of newly-developed BMI and waist cut-off values for Sri Lankan children. Ann Hum Biol. 2013;40:280-5.

10. Rajindrajith S, Pathmeswaran A, Jayasinghe C, Kottahachchi D, Kasturiratne A, de Silva ST, et al. Non-alcoholic fatty liver disease and its associations among adolescents in an urban, Sri Lankan community. BMC Gastroenterol. 2017;17:3-9.

11. Caceres $M$, Teran CG, Rodriguez $S$, Medina M. Prevalence of insulin resistance and its association with metabolic syndrome criteria among Bolivian children and adolescents with obesity. BMC Pediatr. 2008;8:1-6.

12. Chen F, Wang Y, Shan X, Cheng H, Hou D, Zhao X, et al. Association between Childhood Obesity and Metabolic Syndrome: Evidence from a Large Sample of Chinese Children and Adolescents. PLoS One. 2012;7:1-7.

13. Kwiterovich PO. Recognition and management of dyslipidemia in children and adolescents. J Clin Endocrinol Metab. 2008;93:4200-9.

14. Wickramasinghe VP, Arambepola C, Bandara P, Abeysekera M, Kuruppu S, Dilshan P, et al. Distribution of obesity-related metabolic markers among 5-15 year old children from an urban area of Sri Lanka. Ann Hum Biol. 2013;40:168-74. 
15. Benedict M, Zhang X. Non-alcoholic fatty liver disease: An expanded review. World J Hepatol. 2017;9:715-32.

16. Lwanga SK, Lemeshow S, World Health Organization. Sample size determination in health studies: a practical manual. World Health Organization; 1991.

17. de Onis M, Onyango AW, Borghi E, Siyam A, Nishida C, Siekmann J. Development of a WHO growth reference for school-aged children and adolescents. Bull World Health Organ. 2007;85:660-7.

18. Must A, Dallal GE, Dietz WH. Reference data for obesity: 85th and 95th percentiles of body mass index (wt/ht2) and triceps skinfold thickness. Am J Clin Nutr. 1991;53:839-46.

19. Zimmet P, Alberti GKMM, Kaufman F, Tajima N, Silink M, Arslanian S, et al. The metabolic syndrome in children and adolescents - An IDF consensus report. Pediatr Diabetes. 2007;8:299-306.

20. Mccarthy HD, Ellis SM, Cole TJ. Central overweight and obesity in British youth aged 11-16 years: Cross sectional surveys of waist circumference. Bmj. 2003;326:624.

21. Wickramasinghe VP, Lamabadusuriya SP, Cleghorn GJ, Davies PSW. Defining anthropometric cut-off levels related to metabolic risk in a group of Sri Lankan children. Ann Hum Biol. 2011;38:537-43.

22. McCarthy HD, Cole TJ, Fry T, Jebb SA, Prentice AM. Body fat reference curves for children. Int J Obes. 2006;30:598-602.

23. Grundy SM, Stone NJ, Bailey AL, Beam C, Birtcher KK, Blumenthal RS, et al. 2018 AHA/ACC/AACVPR/AAPA/ABC/ACPM/ADA/AGS/APhA/ASPC/NLA/PCNA Guideline on the Management of Blood Cholesterol: A Report of the American College of Cardiology/American Heart Association Task Force on Clinical Practice Guidelines. J Am Coll Cardiol. 2019;73:e285-350.

24. Adeli K, Higgins V, Trajcevski K, White-Al Habeeb N. The Canadian laboratory initiative on pediatric reference intervals: A CALIPER white paper. Crit Rev Clin Lab Sci. 2017;54:358-413.

25. Singh N, Parihar RK, Saini G, Mohan SK, Sharma N, Razaq M. Prevalence of metabolic syndrome in adolescents aged 10-18 years in Jammu, J and K. Indian J Endocrinol Metab. 2013;17:133-7.

26. Shah M, Radia D, Mccarthy HD. Waist circumference centiles for UK South Asian children. Arch Dis Child. 2020;105:80-5.

27. Shaw NJ, Crabtree NJ, Kibirige MS, Fordham JN. Ethnic and gender differences in body fat in British schoolchildren as measured by DXA. Arch Dis Child. 2007;92:872-5. 